\title{
Lasitude and Retrofitting to Bridge
}

\author{
V.D. Sushma and Dr.D.K. Kulkarni
}

\begin{abstract}
Bending moments shear forces, stresses, displacements are important failure modes under traffic loading. However, bridges have so many accredit that it is difficult to analyze their lassitude damages. Numerical simulation is a feasible method of studying such fatigue, displacement, stresses, damages this paper develops bridge stability and safe by using retrofitting technique during heavy traffic and aged bridge. With the purpose to provide a retrofit method with good workability for reinforced concrete (RC) highway bridge columns under severe construction work conditions, a retrofit method with combination of carbon fiber reinforced polymer (CFRP) sheet and steel jacketing has been proposed in this research project. This paper provide an introduction of the proposed retrofit method companying with descriptions on the CFRP-steel bonded connection and RC bridge column provide great stiffness.
\end{abstract}

Keywords--- Displacement, Fatigue Failure, Stresses, Finite Element, Retrofitting.

\section{INTRODUCTION}

$\mathrm{T}$ HIS bridge structure is a built to span physical obstacles without closing the way underneathsuch as a body of water, valley or road, for the purpose of providing passage over the obstacle. There are many different designs that each serve a particular purpose and apply to different situations. Designs of bridges vary depending on the function of the bridge, the nature of the terrain where the bridge is constructed and anchored, the material used to make it, and the funds available to build it. History of bridges started in ancient times, and ever since then architect and engineers improved them to the point they are today-mighty structures that span mountains, lakes and oceans.

Structural togetherness and failure is an aspect of engineering which deals with the ability of a structure to support a designed load (weight, force, etc...) without breaking, tearing apart, or collapsing, and includes the study of breakage that has previously occurred in order to prevent failures in future designs.

Structural togethernessis the term used for the performance characteristic applied to a component, a single structure, or a structure consisting of different components. Structural integrity is the ability of an item to hold together under a load, including its own weight, resisting breakage or bending. It assures that the construction will perform its designed function, during reasonable use, for as long as the designed life of the structure. Items are constructed with structural integrity to ensure that catastrophic failure does not occur, which can result in injuries, severe damage, death, and/or monetary losses.

Structural failure refers to the loss of structural togetherness, which is the loss of the load-carrying capacity of a component or member within a structure, or of the structure itself. Structural failure is initiated when the material is stressed beyond its strength limit, thus causing fracture or excessive deformations. In a well-designed system, a localized failure should not cause immediate or even progressive collapse of the entire structure. Ultimate failure strength is one of the limit states that must be accounted for in structural engineering and structural design.

Bending moments, shear forces, displacements, stresses is an important failure mode for steel structures. In fact, 80-90\% of failures in steel structures are related to fatigue and stresses and displacements. Nowadays, more and more large steel bridges are being constructed worldwide, and some are expected to be vulnerable to laitude-related problems. It is important to study lasitude damage in these bridges. Lasitude analysis for an existing bridge is predominantly based on stress analysis, to get the distribution of stress in structures. Heavy traffic running on this bridge, bridge may significantly change local dynamic behavior and affect the fatigue life of the bridge. Many experimental techniques that have been shown to be successful for structural identification of shortand medium-span bridges cannot simply be scaled-up to longspan bridge. All of these factors make it very difficult to study lassitude damage in long-span bridges with experimental measurement. Correspondingly, numerical simulation is a feasible method to study such lasitude damage. In this bridge Firstly I used up to 50 years corresponding population loads. After I used heavy loads to same bridge and considered further 50 years corresponding population loads and that bridges gave lot fatigues, stresses, displacements and its more than previous 50 years. So observed these laitudeness and used retrofitting techniques to columns and becomes got sufficient results for this bridge.

\section{A. Five Big Reasons Contributing to Bridge Fail}

- Natural calamities.

- Construction failures

- Defective design

- Poor maintenance

- Low grade materials

V.D. Sushma, PG Student, Civil Engineering, SDM College of Engineering, Dharwad, Karnataka, India.E-mail:diggi.sushma@gmail.com

Dr.D.K. Kulkarni, Professor, Civil Engineering, SDM College of Engineering, Karnataka, India.E-mail:dilipkkukulkarni@ rediffmail.com DOI:10.9756/BIJMMI.8173 


\section{B. Objectives of the Project}

In this paper the bridge is analyzed by using STAAD-Pro software.The bridge is analyzed for present and future traffic loading. Comparing these traffic loads retrofitting techniques are adopted.

\section{Methodology}

$I^{\text {st }}$ case: In this case up to 50years of traffic load due to population and corresponding results are arrived. STAAD.Pro software is used for the analysis.

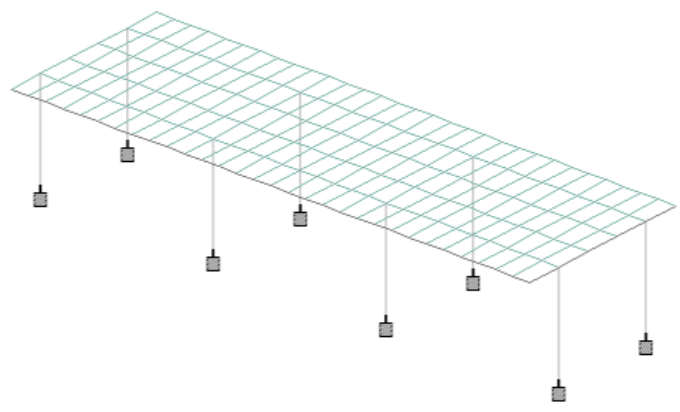

Figure 1: Bridge Model

Table1: Bridge details

\begin{tabular}{|l|l|}
\hline Data & \\
\hline Length of the bridge & $30 \mathrm{~m}$ \\
\hline Width of the bridge & $5 \mathrm{~m}$ \\
\hline Effective span & $10.3 \mathrm{~m}$ \\
\hline Width of the support & $0.3 \mathrm{~m}$ \\
\hline Number of lanes & 02 \\
\hline Slab thickness & $0.2 \mathrm{~m}$ \\
\hline
\end{tabular}

$2^{\text {nd }}$ case: In this case future load for 50years is applied for heavy traffic due to population. Due to heavy movements bridge receives heavy load. Either bridge may carry this heavy load or there is large displacements and stresses, moments along node and beams, this beams is middle of supports. This is caused because of tiredness of bridge. From this point of view this bridge can resist these loads up to some years but it may fail to resist heavy traffic. Because of this purpose retrofitting to same bridge got good results to resist heavy loads. Further tables show case1, case 2 and retrofitting values.

$3^{\text {rd }}$ case: In this case also future load for 50years is applied for heavy traffic due to population. But in this case retrofitting technique is used hence slab is not retrofitted, only columns are retrofitted so got feasible results compare to $2^{\text {nd }}$ case it is sufficient to resist heavy loads.

\section{A. Retrofitting}

Attributing to the merits of high strength, light-weight and outstanding workability,fiber reinforced polymer (FRP) sheet has been widely used in repairing orstrengtheningreinforced concrete (RC) members in the recent decades. As for seismic retrofit of RC highway bridge columns in Japan, FRP sheet is usually used to retrofit columns with premature termination of longitudinal reinforcements without enough development length at the midheight. CFRP sheet was jacketed around the termination sections of the longitudinal reinforcements in the longitudinal direction and circumferential direction to reinforce flexural and shear strength. In some other cases, FRP sheet is also used to reinforce ductility of the columns by jacketing around the plastic hinge in the circumferential direction.

However, it is not an effective method to reinforce the flexural strength of the column base by jacketing FRP sheet in the longitudinal direction. Generally, high elongation is required locally in both of the longitudinal and circumferential directions at the base. Enhancement of ductility capacity of the base can not be obtained because elongation of the FRP sheet is rather lower before breaking. From the point of view, a method with using combination of CFRP sheet and steel jacketing has been proposed. It should be noted for the retrofit method that bonding behavior between CFRP sheet and steel plate is a key issue, because the longitudinal force induced from the additional anchor bolts must be transmitted to CFRP sheet and thus the steel plate should be bonded with CFRP sheet in the inelastic response of the column. 

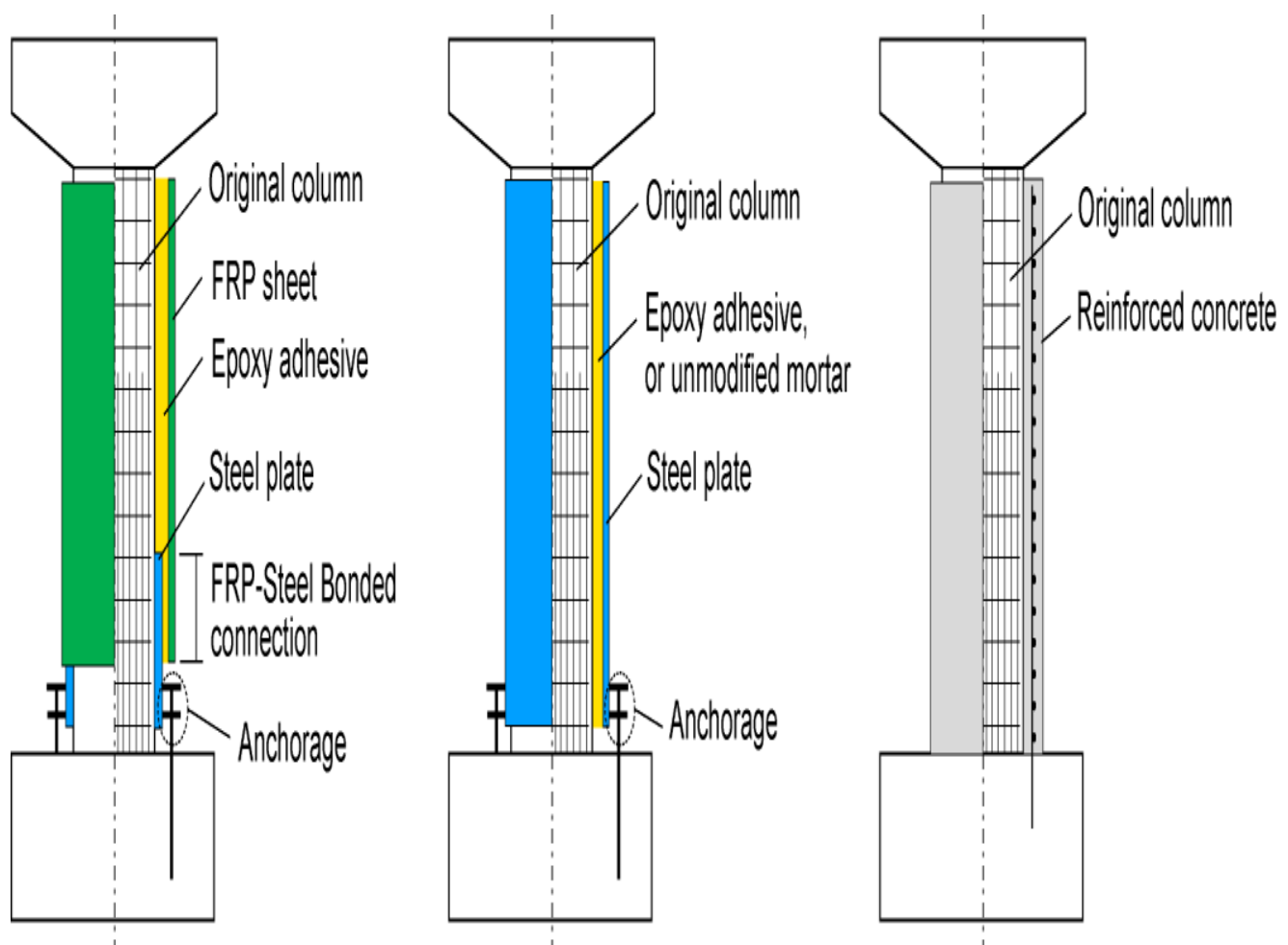

a) Combination (b) Steel Jacketing (c) RC Jacketing and Steel Jacketingof CFRP

Figure 2: Schematics of Seismic Retrofit Methods for RC Bridge Columns

\section{Data}

Length of bridge $=30 \mathrm{~m}$

Width of the supports $=0.5 \mathrm{~m}$

Width of the bridge $=5 \mathrm{~m}$

Effective span $=10.5 \mathrm{~m}$

After retrofitting width of support and effective span are increased.

\section{RESULTS AND DISCUSSION}

Table 2: Node Displacements

\begin{tabular}{|l|l|l|l|}
\hline Nodes & $\begin{array}{l}1^{\text {st }} \text { case } \\
\text { displacement(mm) }\end{array}$ & $\begin{array}{l}2^{\text {nd }} \text { case } \\
\text { displacement }(\mathrm{mm})\end{array}$ & $\begin{array}{l}\text { Retrofitting } \\
\text { displacement(mm) }\end{array}$ \\
\hline $4^{\text {th }}$ & 1.77 & 5.105 & 1.9 \\
\hline $5^{\text {th }}$ & 1.857 & 4.9 & 1.7 \\
\hline $12^{\text {th }}$ & 1.596 & 3.9 & 2.39 \\
\hline $13^{\text {th }}$ & 1.551 & 3.91 & 2.39 \\
\hline $20^{\text {th }}$ & 0.019 & 0.083 & 0.074 \\
\hline $21^{\text {st }}$ & 0.022 & 0.078 & 0.080 \\
\hline $28^{\text {th }}$ & 0.005 & 0.042 & 0.053 \\
\hline $29^{\text {th }}$ & 0.017 & 0.270 & 0.032 \\
\hline $57^{\text {th }}$ & 15.517 & 23.434 & 15.575 \\
\hline $61^{\text {st }}$ & 7.555 & 40.05 & 29.025 \\
\hline $111^{\text {th }}$ & 3.415 & 6.99 & 3.017 \\
\hline $115^{\text {th }}$ & 2.070 & 9.012 & 4.088 \\
\hline $165^{\text {th }}$ & 0.711 & 1.722 & 0.419 \\
\hline $169^{\text {th }}$ & 0.611 & 1.921 & 0486 \\
\hline & & & \\
\hline
\end{tabular}

Table 3: Beam Displacements

\begin{tabular}{|l|l|l|l|}
\hline Beams & $\begin{array}{l}1^{\text {st }} \text { case } \\
\text { displacement } \\
(\mathrm{mm})\end{array}$ & $\begin{array}{l}2^{\text {nd }} \\
\text { displacement } \\
(\mathrm{mm})\end{array}$ & $\begin{array}{l}\text { Retrofitting } \\
\text { displacement }(\mathrm{mm})\end{array}$ \\
\hline $4^{\text {th }}$ & 0.325 & 0.895 & 0.550 \\
\hline $7^{\text {th }}$ & 0.252 & 0.627 & 0.460 \\
\hline $30^{\text {th }}$ & 0.006 & 0.021 & 0.018 \\
\hline $43^{\text {rd }}$ & 0.001 & 0.002 & 0.003 \\
\hline $92^{\text {nd }}$ & 0.195 & 0.315 & 0.243 \\
\hline $99^{\text {th }}$ & 0.098 & 0.563 & 0.473 \\
\hline $196^{\text {th }}$ & 0.028 & 0.071 & 0.028 \\
\hline $203^{\text {rd }}$ & 0.022 & 0.075 & 0.035 \\
\hline $300^{\text {th }}$ & 0.006 & 0.015 & 0.003 \\
\hline $307^{\text {th }}$ & 0.005 & 0.016 & 0.004 \\
\hline
\end{tabular}

Table 4: Bending Moments

\begin{tabular}{|l|l|l|l|}
\hline Beams & $1^{\text {st }}$ case $(\mathrm{kNm})$ & $2^{\text {nd }}$ case $(\mathrm{kNm})$ & Retrofitting $(\mathrm{kNm})$ \\
\hline $4^{\text {th }}$ & 14.060 & 35.400 & 22.700 \\
\hline $17^{\text {th }}$ & 14.425 & 18.657 & 13.526 \\
\hline $30^{\text {th }}$ & 0.209 & 0.650 & 0.535 \\
\hline $43^{\text {rd }}$ & 0.064 & 0.142 & 0.183 \\
\hline $92^{\text {nd }}$ & 25.953 & 41.117 & 32.000 \\
\hline $99^{\text {th }}$ & 13.168 & 70.980 & 59.715 \\
\hline $196^{\text {th }}$ & 3.860 & 9.264 & 4.326 \\
\hline $203^{\text {rd }}$ & 3.293 & 10.334 & 5.018 \\
\hline $300^{\text {th }}$ & 0.800 & 2.071 & 0.532 \\
\hline $307^{\text {th }}$ & 0.742 & 2.270 & 0.590 \\
\hline
\end{tabular}


Table 5: Shear Forces

\begin{tabular}{|c|c|c|c|}
\hline Beams & $1^{\text {st }}$ case $(k N)$ & 2nd case $(k N)$ & $\begin{array}{c}\text { Retrofitting } \\
(k N)\end{array}$ \\
\hline $4^{\text {th }}$ & 4.524 & 9.51 & 6.53 \\
\hline $17^{\text {th }}$ & 0.150 & 0.362 & 0.029 \\
\hline $30^{\text {th }}$ & 0.025 & 0.041 & 0.009 \\
\hline $43^{\text {rd }}$ & 0.041 & 0.083 & 0.075 \\
\hline $92^{\text {nd }}$ & 6.110 & 8.442 & 6.96 \\
\hline $99^{\text {th }}$ & 3.334 & 9.930 & 8.43 \\
\hline $196^{\text {th }}$ & 1.134 & 3.642 & 2.001 \\
\hline $203^{\text {rd }}$ & 1.332 & 3.163 & 1.880 \\
\hline $300^{\text {th }}$ & 0.221 & 0.605 & 0.267 \\
\hline $307^{\text {th }}$ & 0.221 & 0.607 & 0.531 \\
\hline
\end{tabular}

Table 6: Tensile Stresses

\begin{tabular}{|l|l|l|l|}
\hline beam & 1 st case $\left(\mathrm{N} / \mathrm{mm}^{2}\right)$ & 2nd case $\left(\mathrm{N} / \mathrm{mm}^{2}\right)$ & Retrofitting $\left(\mathrm{N} / \mathrm{mm}^{2}\right)$ \\
\hline 4 & 3.129 & 7.863 & 5.04 \\
\hline 17 & 1.679 & 4.139 & 3.009 \\
\hline 30 & 0.048 & 0.147 & 0.125 \\
\hline 43 & 0.017 & 0.039 & 0.05 \\
\hline 92 & 5.739 & 9.099 & 7.033 \\
\hline 99 & 2.914 & 15.7 & 13.129 \\
\hline 196 & 0.853 & 2.1 & 0.965 \\
\hline 203 & 0.732 & 2.286 & 1.109 \\
\hline 300 & 0.173 & 0.453 & 0.113 \\
\hline 307 & 0.163 & 0.474 & 0.119 \\
\hline
\end{tabular}

Table 7: Compressive Stresses

\begin{tabular}{|l|l|l|l|}
\hline $\begin{array}{l}\text { bea } \\
m\end{array}$ & $\begin{array}{l}\text { 1st case } \\
\left(\mathrm{N} / \mathrm{mm}^{2}\right)\end{array}$ & $\begin{array}{l}\text { 2nd case } \\
\left(\mathrm{N} / \mathrm{mm}^{2}\right)\end{array}$ & $\begin{array}{l}\text { Retrofitting } \\
\left(\mathrm{N} / \mathrm{mm}^{2}\right)\end{array}$ \\
\hline 4 & 3.142 & 7.902 & 5.115 \\
\hline 17 & 1.687 & 4.158 & 3.063 \\
\hline 30 & 0.047 & 0.145 & 0.122 \\
\hline 43 & 0.013 & 0.028 & 0.04 \\
\hline 92 & 5.798 & 9.2 & 7.194 \\
\hline 99 & 2.941 & 15.9 & 13.425 \\
\hline 196 & 0.863 & 2.1 & 0.962 \\
\hline 203 & 0.733 & 2.31 & 1.123 \\
\hline 300 & 0.183 & 0.47 & 0.125 \\
\hline 307 & 0.168 & 0.498 & 0.143 \\
\hline
\end{tabular}

A. Comparision of Results Between Displacements, Stresses, Bending Moments, Shear Forces

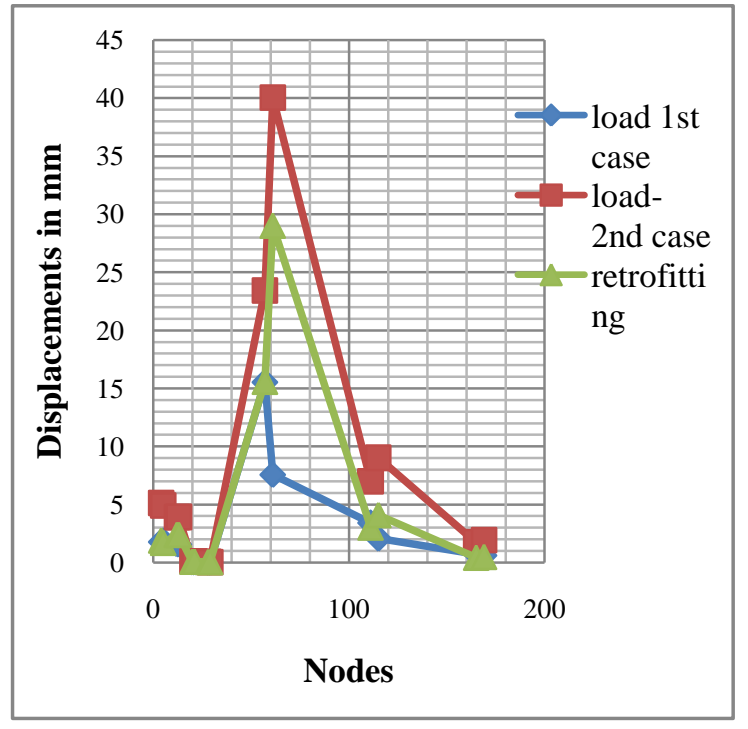

Figure 3: Node Displacements in Between Supports

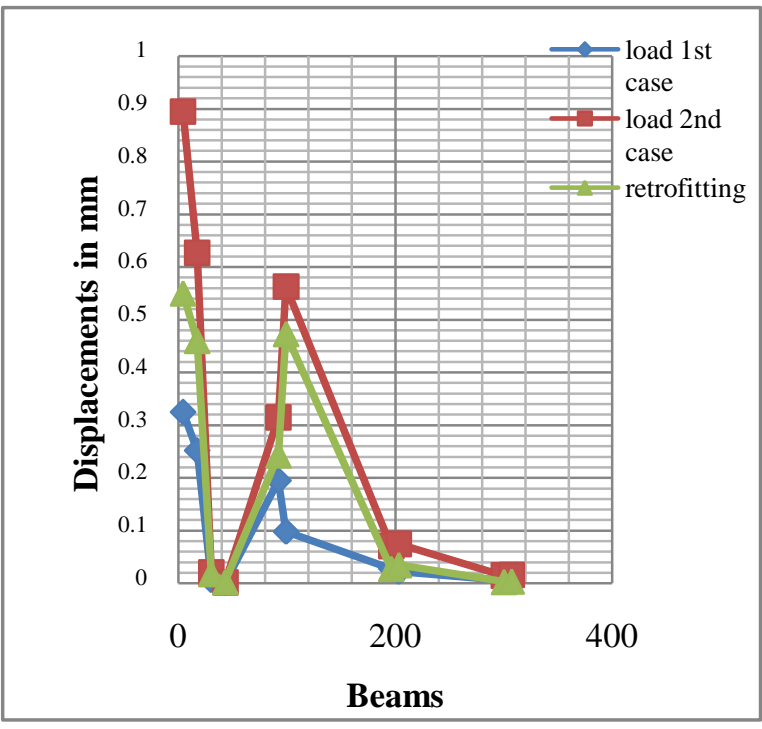

Figure 4: Beam Displacements in between Supports

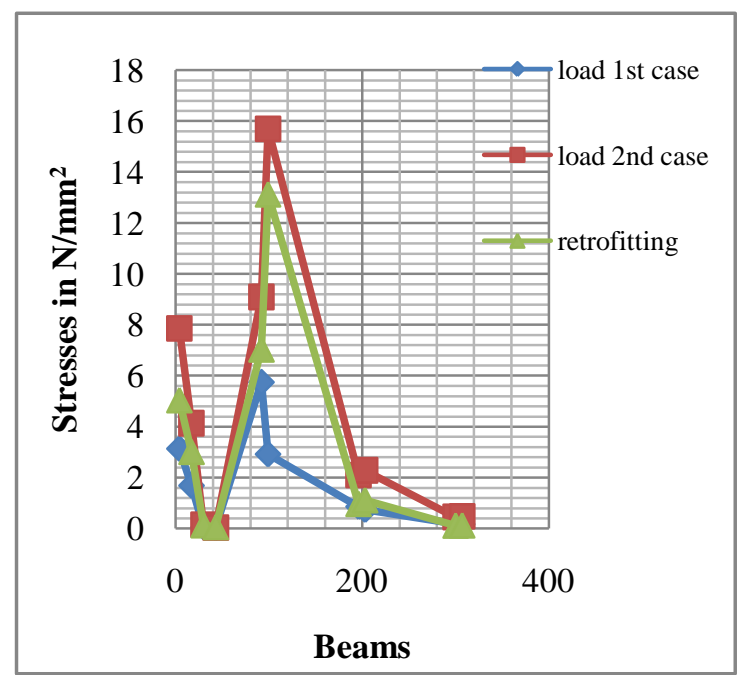

Figure 5: Tensile Stresses

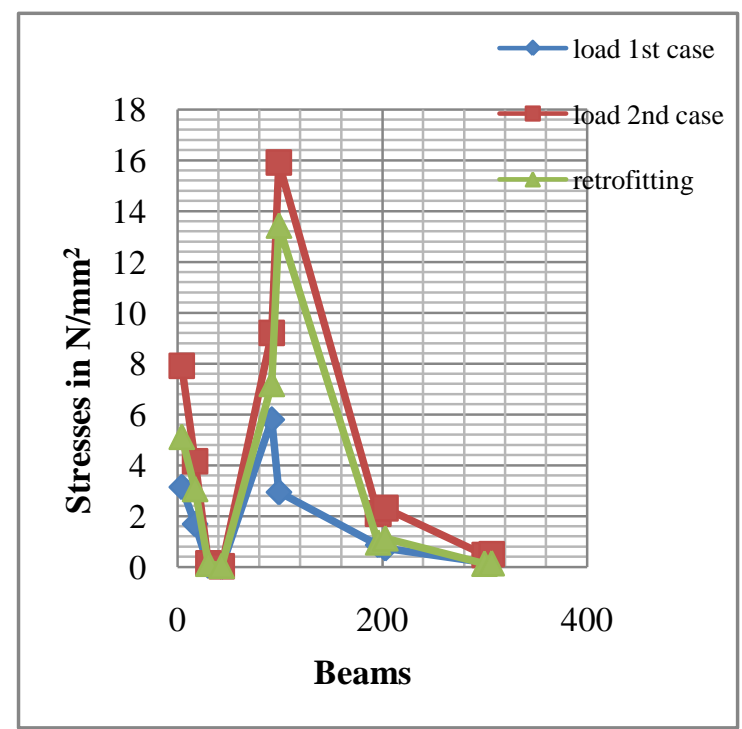

Figure 6: Compressive Stresses 


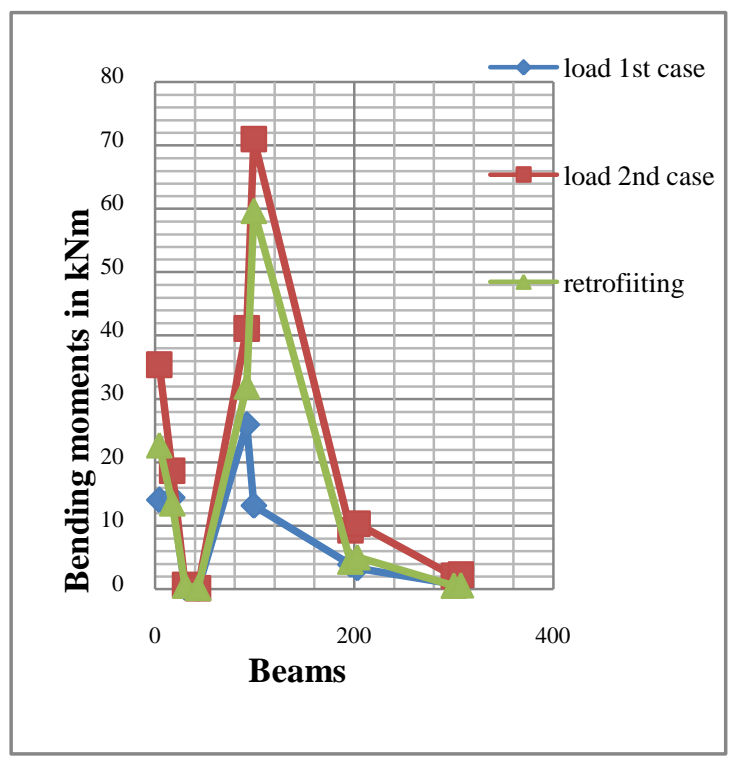

Figure 7: Bending Moments

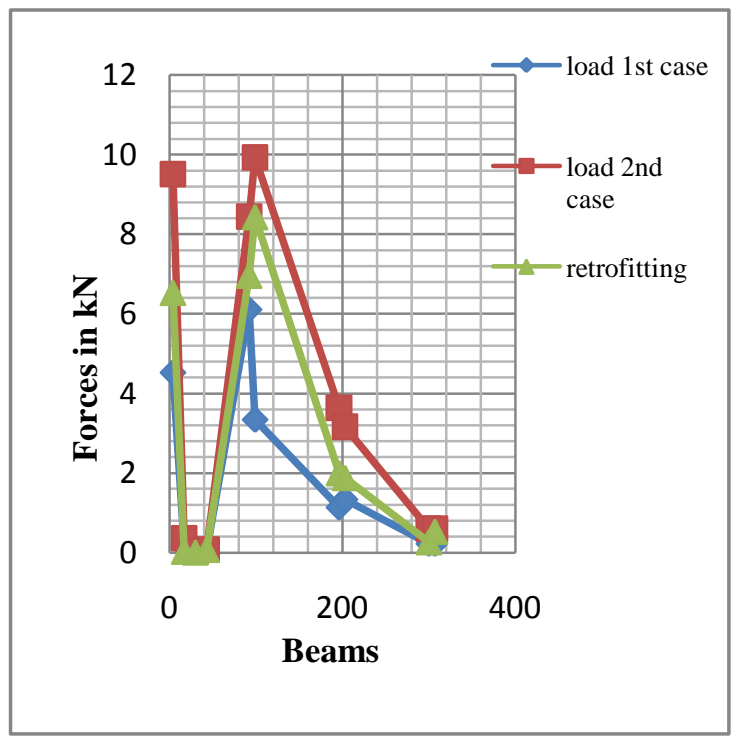

Figure 8: Shear Force

\section{B. Overall Comparision}

Maximum Stresses

\begin{tabular}{|l|l|l|l|}
\hline & $1^{\text {st }}$ case & $2^{\text {nd }}$ case & Retrofitting \\
\hline $\begin{array}{l}\text { Compressive stresses } \\
\left(\mathrm{N} / \mathrm{mm}^{2}\right)\end{array}$ & 20.26 & 34.024 & 14.464 \\
\hline $\begin{array}{l}\text { Tensile stresses } \\
\left(\mathrm{N} / \mathrm{mm}^{2}\right)\end{array}$ & 17.942 & 31.748 & 13.577 \\
\hline
\end{tabular}

Maximum Displacements

\begin{tabular}{|l|l|l|l|}
\hline & $1^{\text {st }}$ case & $2^{\text {nd }}$ case & Retrofitting \\
\hline Displacements $(\mathrm{mm})$ & 1.777 & 2.833 & 0.750 \\
\hline
\end{tabular}

Over All Reactions

\begin{tabular}{|l|l|l|l|}
\hline & $1^{\text {st }}$ case & $2^{\text {nd }}$ case & Retrofitting \\
\hline Moments $(\mathrm{kNm})$ & 1359.1 & 3191.99 & 3191.9 \\
\hline Forces $(\mathrm{KN})$ & 282 & 699.9 & 699.9 \\
\hline
\end{tabular}

After retrofitting bridge is capable of carrying heavy traffic load.

\section{CONCLUSION}

A large FE model of a bridge was thrive in this paper. In order to be suitable for lasitude stress analysis, the developed FE model express the spatial presentation of the original structure. Consider all above results we can easily use retrofitting technique without disturbing the traffic and also can also save bridges about many years. During the remove of the bridge responses under heavy traffic loadings. The computed stress spectra in the bridge could be used for subsequent lasitude damage analyses. These results show that the proposed FE model in this paper is efficient for lassitude analysi Retrofit method with using a combination of CFRP sheet jacketing and steel jacketing was proposed in this research project with the purpose to provide a retrofit method for RC bridge columns under severe construction work conditions.

\section{SCOPE FOR FUTURE WORK}

This work can be extended by using deflection to determine the failure. Other methods of retrofittings are concrete jacketing, composite material jacketscan be implemented.

\section{REFERENCES}

[1] J. Hoshikuma and S. Unjoh, "Seismic Retrofit of Existing Reinforced Concrete Columns by Steel jacketing", Proceedings of the Second ItalyJapan Workshop on Seismic Design and Retrofit of Bridges, Rome, Italy, Pp. 413-428, 1997.

[2] T. Chan, Z.X. Li, "Fatigue damage analysis of large suspension bridge using finite element method", Journal of Engineering Structure.

[3] W.R. Charles, M. Gregory, C. Paul, A. Kayoko and W. Scott, "Dynamic response and fatigue of steel Tied-Arch Bridge", Journal of Bridge Engineering, Vol. 5, Pp. 14-21, 2000.

[4] G.F. Zhang and S. Unjoh, "A Retrofit Method for Upgrading Seismic Performance of RC Columns with Termination of Main Reinforcements", Proceedings of the 12th Symposium on Ductility Design Method for Bridges, JSCE, (in Japanese). Vol. 1, Pp. 47-52, 2009 . 